\title{
Kirchner Growth Medium
}

National Cancer Institute

\section{Source}

National Cancer Institute. Kirchner Growth Medium. NCI Thesaurus. Code C128949.

A liquid growth medium mainly consisting of sodium dihydrogen phosphate, potassium

dihydrogen phosphate, magnesium sulphate, trisodium citrate, L-asparag ine and phenol red, which is developed for the culture and recovery of Mycobacteria. 